\title{
AS PRÁTICAS EDUCATIVAS PARENTAIS E A EXPERIÊNCIA DAS CRIANÇAS
}

\author{
CléopÂtre MonTANdon ${ }^{* *}$
}

\begin{abstract}
RESUMO: Este artigo tenta mostrar o quanto é importante estudar a experiência das crianças e seus pontos de vista para podermos compreender os diferentes fenômenos sociais que lhes dizem respeito. $\mathrm{Na}$ perspectiva da sociologia da infância, sua experiência é considerada no âmbito das estruturas sociais e do contexto particular nos quais se insere. A partir de vários exemplos no campo da educação de crianças, a autora argumenta que não basta examinar as práticas educativas de seus educadores, mas que é necessário compreender as perspectivas das crianças ou, dito de modo mais simples, que importa analisar não apenas o que os educadores fazem com as crianças, como também o que estas fazem com o que se faz com elas. Duas pesquisas são apresentadas para apoiar essa abordagem: a primeira diz respeito à experiência que as crianças têm de sua educação no âmbito familiar e escolar; a segunda trata de um objetivo particular dos educadores modernos: o desenvolvimento da autonomia das crianças. Em ambos os estudos, a experiência das crianças foi apreendida por intermédio de suas representações, emoções e ações, e foi situada segundo suas características sociais e culturais.
\end{abstract}

Palavras-chave: Sociologia da infância. Educação. Pais. Autonomia. Representações.

\section{PaReNTAl eduCATION PRACTICES AND CHILDREN'S EXPERIENCE}

ABSTRACT: This paper tries to show that the experience of children and their points of view are paramount when one wants to understand the various social phenomena that concern them. According to the perspective of the Sociology of Childhood, children's experience is analyzed in the framework of the social structures and

\footnotetext{
* Tradução de Alain François, com revisão técnica de Ivany Pino.

** Professora da Universidade de Genebra (Suíça). E-mail: cleopatre.Montandon@pse.unige.ch
}

Educ. Soc., Campinas, vol. 26, n. 91, p. 485-507, Maio/Ago. 2005 
the particular contexts in which it takes place. Using different examples from the field of the education of children, the author argues that it is not sufficient to examine the educational practices of adults; it is equally important to examine the children's perspective. In other words, we should take into consideration what the children do with what is done to them. Two studies are presented to support this approach: the first one concerns the experience children have of their education in their family and school; the second one concerns a particular objective of modern education, namely the development of children's autonomy. In both studies, the experience of children is analyzed in terms of their representations, emotions and actions, with due consideration to their social and cultural characteristics.

Key words: Sociology of childhood. Education. Parents. Autonomy. Perspectives.

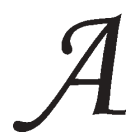

$s$ relaçôes entre pais e filhos costumam suscitar debates apaixonantes e apaixonados e, nestes últimos tempos, passaram a focalizar mais particularmente a relação de autoridade. ${ }^{1}$ No Ocidente, hoje em dia, observa-se que as mudanças sociais têm levado a um deslocamento nas relações de autoridade pais/filhos, de um modelo baseado na imposição e no controle a outro fundamentado na participação e na negociação. Embora este fato alegre quem vê nele um exemplo democrático de evolução, ele costuma assustar aqueles que, pelo contrário, estão convictos de que reforça o individualismo e ameaça a civilização democrática (Roussel, 2001).

Contudo, pode-se afirmar que os pais não têm mais autoridade? E se fosse o caso, poder-se-ia asseverar que sua influência sobre seus filhos é determinante ou que estão na origem dos problemas atribuídos a estes? Para tentar responder a essas indagaçóes, propomos duas abordagens: 1) examinar brevemente a maneira como as práticas educativas dos pais foram analisadas nas ciências sociais; 2 ) introduzir um ponto de vista essencial e por muito tempo desprezado: o dos destinatários dessa educação, as crianças.

\section{As práticas educativas dos pais}

Hoje em dia, as mídias costumam alardear que as relações entre adultos e crianças nunca foram tão difíceis. Quase toda semana, apresentam pais enleados, desnorteados, demissionários ou docentes estressados, 
esgotados, desiludidos e exibem relações conflitantes e até violentas entre adultos e crianças. Atribuem-se inúmeros males à deterioração da relação entre educadores e crianças e mais particularmente ao enfraquecimento da autoridade dos pais e docentes: violências, delinqüência, fracassos escolares etc. Para alguns, os problemas devem-se à situação difícil dos pais. Para outros, entretanto, os problemas estariam diretamente vinculados ao comportamento dos pais, quer porque não se opõem a seus filhos, o que faz com que estes não tolerem frustrações e se tornem insuportáveis; quer porque os consideram como iguais, como adultos. Seu desenvolvimento é então afetado: eles perdem sua despreocupação, podem ser levados a sustentar seus pais na dificuldade e sofrerem abusos por aqueles que se aproveitam de sua inocência. Ora, a problematização dos filhos não é nova:

Se pudesse subir até o ponto mais alto de Atenas, levantaria minha voz para proclamar: "Concidadãos, por que revirais e raspais cada pedra para acumular riquezas, mas cuidais tão pouco de vossos filhos a quem um dia ides ceder tudo".

Nossa juventude adora o luxo, é mal-educada, caçoa da autoridade e não tem o menor respeito pelos mais velhos. Nossos filhos hoje são verdadeiros tiranos. (Sócrates)

Contudo, o que dizem as pesquisas? Será que permitem atribuir um papel tão importante às práticas educativas dos adultos, concreta e teoricamente? Antigamente, eram os filósofos e homens de religião que discutiam as questôes de educação. Do século XX em diante, porém, psicólogos, antropólogos e sociólogos, pedagogos passaram a investir maciçamente nesse campo, analisando a natureza da educação parental, seus determinantes e suas conseqüências, desenvolvendo teorias cada vez mais reproduzidas pelas mídias. Entre os trabalhos sobre a educação parental, vamos nos deter nos seguintes: a) os que buscam explicar as diferenças entre as práticas educativas dos pais e b) os que estudam as consequiências das diferentes maneiras de educar dos pais sobre o desenvolvimento de seus filhos.

\section{As práticas educativas dos pais: algumas tentativas para explicar suas diferenças}

Os primeiros trabalhos desses pesquisadores já mostraram que existem diferentes tipos de práticas dos pais e, antes de tentar explicá- 
las, propuseram tipologias. Estas distinguem geralmente atitudes mais ou menos autocráticas ou democráticas, persuasivas ou coercitivas. Baumrind (1971), por exemplo, propôs três estilos: o autoritário, quando os pais controlam muito mas apóiam pouco a criança, tendendo a educar segundo regras que não se discutem; o permissivo, quando aqueles exercem um controle fraco e um apoio forte, e tendem a aceitar os desejos da criança, exigindo pouco dela; e o "authoritative", no qual os pais ao mesmo tempo controlam e apóiam seus filhos, fixam-lhes regras a respeitar mas, simultaneamente, encorajam sua independência, são exigentes e atentos. Ela propôs um quarto estilo, o não-envolvido ("uninvolved"), quando os pais têm uma atitude caracterizada pela indiferença e até pela negligência ou rejeição.

Embora esses estilos tenham sido retrabalhados e precisados, os debates atuais apenas retêm as generalizaçôes sobre a pretensa ausência de autoridade dos pais. Ora, o que nos diz a pesquisa de campo? Em muitos lugares da Europa, constata-se claramente que houve um deslocamento e que as práticas democráticas se substituem às práticas autoritárias (Du Bois-Reymond et al., 2001; Montandon \& Longchamp, 2003). As razões são múltiplas. Entre outras, citaremos a elevação geral do nível de educação, a emancipação e o trabalho das mulheres ou ainda a democratização das relações entre os sexos no interior do casal. Como escrevera Norbert Elias (1993), ocorreu uma passagem de um modelo familiar baseado no comando para um modelo baseado na negociação.

Contudo, isso não quer dizer que o estilo negociador substituiu os outros estilos, nem que negociação seja sinônimo de abandono da autoridade. François de Singly enfatiza que, entre as famílias que estudou, "nenhuma funciona segundo um princípio explícito de recusa da autoridade" (2002). Nas famílias, ainda existem certas proibições e regras que os pais não discutem e os filhos aprendem que, se algumas coisas são negociáveis, outras não o são.

Inúmeras pesquisas tentaram isolar os fatores que influenciam os estilos de práticas e atitudes educativas dos pais e o efeito destas sobre as crianças, e existem textos de sínteses muito completos desses trabalhos (Peterson \& Rollins, 1987; Pourtois \& Desmet, 1989).

Um primeiro conjunto de pesquisas tentou explicar as práticas dos pais pelas estruturas familiais, procurando mostrar que existe uma rela- 
ção entre a composição das famílias (número de filhos na família, ordem de nascimento e sexo), ou ainda outras características (separações, divórcio, viuvez, recomposição familiar), e as práticas educativas dos pais (Maccoby, 1980; Baumrind, 1980). Assim, pesquisadores acharam que o sexo da criança influencia os modos de educação, os pais sendo mais estritos com suas filhas que com seus filhos, ou ainda que o divórcio dos pais tem efeitos negativos sobre suas práticas.

Podem-se generalizar essas observaçôes? Numerosos trabalhos vieram mitigá-las, ao mostrarem, por exemplo, que nem sempre o sexo da criança determina as práticas dos pais e que a diferença de tratamento das moças e dos rapazes tem a ver com o pertencimento social ou cultural dos pais (Best \& Williams, 1997; Segal et al., 1999). Outros mostraram que não há vínculo automático entre divórcio e práticas parentais problemáticas, e que se devem levar em conta as condiçōes econômicas em que a criança vive depois do divórcio (Amato \& Booth, 1997; Furstenberg, 1999).

Um segundo conjunto de trabalhos tentou explicar as práticas educativas dos pais pelo pertencimento social das famílias. Segundo eles, os pais de classe média tenderiam a manifestar mais controle de si quando de suas interaçōes com a criança: chamam-na à razão, exercem uma disciplina dentro de limites claramente definidos, negociam com ela, recorrem a punições e recompensas que levam em conta as motivaçóes da criança e fazem planos para seu êxito em longo prazo. Em contraste, os pais das classes populares seriam menos propensos a elaborar um projeto educativo para seus filhos e a dedicar tempo para explicar os motivos de suas exigências, e tenderiam a satisfazer seus caprichos e a puni-los sem muito se preocupar sobre a intenção por trás de seus atos (Gecas, 1979).

Muito rapidamente, entretanto, ficou evidente que trabalhar sobre correlações globais entre meios sociais e práticas educativas familiais levava a interpretações que não permitem considerar variações interindividuais e nuances de atitudes e práticas dentro dos meios sociais. Os raros trabalhos que aprofundam esses pontos hoje em dia, isto é, que conduzem estudos de caso nas famílias, mostram a complexidade do problema: a multiplicidade de fatores que se devem levar em conta, além do pertencimento a um meio social (Clark, 1983; Lahire, 1995), como, por exemplo, a história da família, o tipo de funcionamento familiar, a integração da família na comunidade etc. 
Em Genebra, um estudo tentou ultrapassar as correlações entre meio social e práticas dos pais, ao emitir a hipótese de que, dentro do mesmo meio, as famílias podem ter funcionamentos diferentes, os quais se refletem nas suas maneiras de educar e socializar seus filhos (Kellerhals \& Montandon, 1991). Encontraram, por exemplo, que nas famílias de tipo "bastião", nas quais o valor de consenso é elevado e o aspecto caseiro acentuado, os pais tendem a encorajar nos seus filhos a prontidão para a obediência e a controlá-los. Em contrapartida, nas famílias de tipo "associação", nas quais o valor da independência é elevado, os pais tendem a valorizar um filho que se caracteriza pela autodeterminação, pela aptidão de interação com terceiros, e a favorecer a negociação e o estabelecimento de contratos com eles. Nossa pesquisa mostrou que tanto o meio social como o tipo familiar (quatro tipos ao todo) exercem uma influência sobre os estilos educativos dos pais, contribuindo a matizar o quadro.

Mas ainda resta muito a se fazer, como mostra a Figura 1, a seguir. Por exemplo, não se leva bastante em consideração a evolução do contexto familiar com o tempo. Toda família tem um ciclo de vida. Existem períodos estáveis, outros de reorganização ou de crise. As interações dentro da família modificam-se. Além do mais, não se devem ignorar vários acontecimentos, como desemprego, doença, acidentes, nascimento de uma criança deficiente, que produzem transformações nas relações, reestruturaçoes, e mudanças nas práticas.

Outros trabalhos mostraram que importa levar em conta não apenas o meio social como também a cultura à qual as famílias pertencem, se quisermos compreender melhor o sentido de suas práticas educativas. Um estudo realizado em Portugal mostra que as práticas dos pais autoritários, nesse país, não têm a mesma conotação negativa que nos Estados Unidos ou em outros países europeus (Fontaine, 1990). Elas são consideradas uma dimensão normal da função educativa dos pais e não são incompatíveis com manifestações de ternura e de afeto. Não se associa nenhuma dramatização ou culpabilização às práticas autoritárias (idem, ibid.). Isso ressalta claramente o quanto se deve submeter a análise das práticas à prova da comparação intercultural.

Outros fatores importantes a se considerar são as representações que as famílias têm da infância, dos filhos ou ainda da autoridade. Estas estão vinculadas ao meio social dos pais, e também devem muito às suas origens culturais. Quando a criança era percebida como um ser de 


\section{Figura 1}

(Algumas determinantes socioculturais da educação familiar)

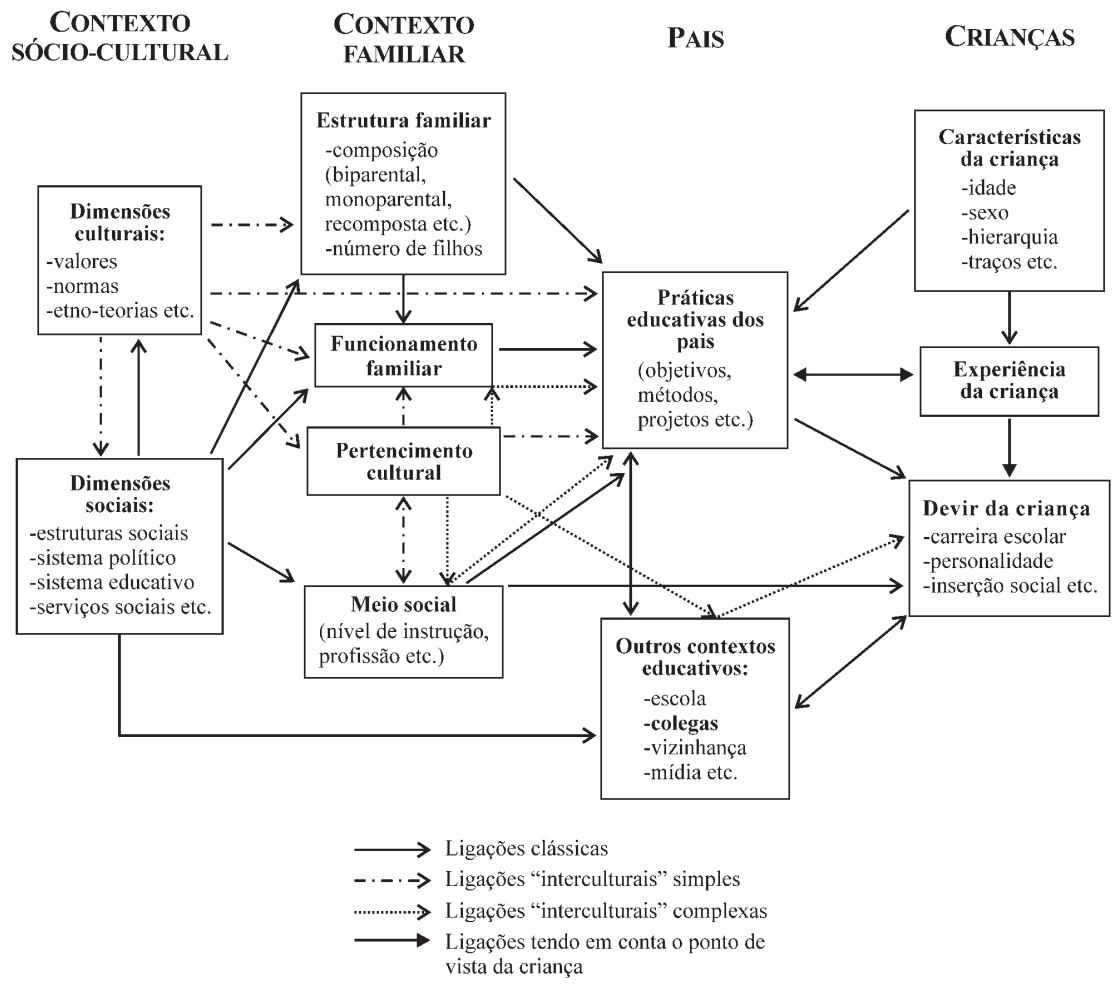

pecado, os pais achavam natural puni-la para endireitá-la. Hoje em dia, percebida como uma pessoa plena, as práticas educativas encontram-se necessariamente modificadas. Seria, entretanto, um erro pensar que nas sociedades ocidentais todos os pais têm as mesmas representações ou que as interpretam do mesmo modo no plano das práticas. Numa cidade como Genebra, diferentes modelos coexistem: se o modelo autoritário estatutário estrito, no qual a autoridade não se discute, é minoritário, ele continua presente (5\%). O modelo hegemônico é o modelo estruturante $(51 \%)$, em que os pais pensam que a autoridade é necessária para fixar pontos de referência para a criança mas deve ser 
explicada. Em seguida, vem o modelo persuasivo (44\%), no qual a autoridade é importante mas pode ser discutida com a criança (Montandon \& Longchamp, 2003).

Por mais que isso possa desagradar aos que anunciam seu definhamento, a autoridade parental é sempre reconhecida como indispensável, embora apresente várias facetas. Como em outros lugares, essas diversas representações da autoridade têm a montante uma relação com o estatuto social dos pais e com sua formação e, a jusante, um vínculo com as práticas. Os pais que têm uma visão persuasiva, por exemplo, tendem a deixar seus filhos participarem das decisões que lhes dizem respeito mais freqüentemente que aqueles pais os quais têm uma visão estrita (idem, ibid.).

\section{As conseqüências das práticas socializadoras dos pais: uma questão controvertida}

Também é preciso matizar os resultados das pesquisas sobre as conseqüências que as práticas educativas dos pais têm sobre os filhos. De modo geral, os trabalhos que enfocam as influências dos pais afirmam que suas condutas afetam a personalidade e outras características dos filhos. Alguns trabalhos, por exemplo, relacionaram os estilos educativos e o desenvolvimento da criança no plano de sua personalidade assim como no de suas relações com os outros. Dessa forma, Baumrind (1966, 1971), que definiu os estilos educativos autoritário, permissivo e "authoritative" - equilibrado -, mostrou que os filhos de pais autoritários são menos competentes tanto no plano escolar quanto no plano das relações com os outros. Outras pesquisas testaram essas mesmas hipóteses com outras características e obtiveram resultados semelhantes (Dornbusch et al., 1987). Assim, observou-se que o amor-próprio das crianças varia segundo os graus de autonomia e de apoio concedidos por seus pais: quanto mais o estilo parental se caracteriza por uma comunicação fraca e uma coerção e um controle vigorosos, mais o amor-próprio das crianças é frágil, e vice-versa (Gecas, 1979; Demo et al., 1987).

Os trabalhos sobre as conseqüências não deixaram de levantar importantes problemas conceituais e metodológicos. Sendo as variáveis intermediárias numerosas, como mostra a Figura 1, elas são dificilmente controláveis. Uns pesquisadores mostraram que o estilo "equilibrado" de 
Baumrind não tem os efeitos positivos que seriam de se esperar em crianças oriundas de uma cultura asiática (Dornbusch et al., 1987) e que as crianças asiáticas que mais tinham êxito na escola eram aquelas às quais os pais aplicavam um estilo autoritário. Chao (1994) argumenta que, se o estilo parental "equilibrado" é de algum modo adaptado à cultura norte-americana, ele não o é necessariamente a outros grupos culturais. Os pais na China e os pais chineses imigrados manifestam-se por um grau de controle mais elevado que o dos americanos brancos. Logo, na cultura chinesa, o estilo autoritário produziria melhores resultados (Lin \& Fu, 1990), o que não quer dizer que sua "importação" para outros contextos culturais seja necessariamente recomendada.

Outros fatores podem também suspender ou curto-circuitar a influência do estilo educativo. No caso de divórico, por exemplo, os transtornos que lhe são associados, a degradação da situação financeira do pai ou da mãe que tem a guarda, a ruptura dos vínculos sociais, provocada pela mudança de casa, para o pai ou a mãe e para a criança, são outras variáveis que devem ser levadas em conta, em vez de tudo atribuir à deterioração da relação educativa ou afetiva entre pai/mãe e filho(s).

A relação educativa deve também ser situada no contexto do conjunto das relações da criança, especificamente com os mais próximos, nas fronteiras da família, como os avôs por exemplo, os sogros, os meios-irmãos e meias-irmãs, os outros membros de uma família recomposta, ou a rede de parentesco. $\mathrm{O}$ efeito do estilo educativo dos pais pode ser quer reduzido, anulado ou ampliado pelas interaçôes com essas outras pessoas próximas. Do mesmo modo, pode ser anulado ou ampliado, e até perturbado, pelo estilo educativo que a criança conhece na escola ou em outros contextos educacionais.

Ainda no plano do estilo de relação educativa e afetiva entre os pais e a criança, é difícil saber se é a ação parental que tem efeitos particulares sobre a criança ou se os pais desenvolvem seu estilo educativo em reação aos comportamentos da criança. A maioria das pesquisas não permite responder a esta pergunta, pois enfoca uma única criança nas famílias estudadas e não se pode saber se os pais utilizam os mesmos modos de socialização com os outros filhos também ou se modulam sua relação e seus comportamentos em função de cada criança, o que poderia em parte explicar as diferenças no desenvolvimento entre irmã(o)s. 
Por isso, há quem considere a família "como um ambiente não compartilhado", o que significa que filhos que crescem na mesma família não compartilham necessariamente de um ambiente de interação idêntico (Plomin et al., 1994). Segundo eles, para cada criança tomada separadamente, as relações diádicas com os outros membros da família têm suas peculiaridades e a mesma família constitui um contexto diferente, não partilhado pelos irmã $(0) s$.

Como vemos, o quadro é complexo. Obviamente, as práticas que encorajam a autonomia são exigentes para o indivíduo e podem ter um efeito desestabilizador sobre a criança e seus pais. É o preço da democratização, por assim dizer. No processo educativo, alcançar um equilíbrio entre excesso de submissão e excesso de liberdade, questão que preocupou Locke, Rousseau e tantos outros, é um exercício delicado. Além do mais, quando a autonomia se torna uma norma para um indivíduo, ela suscita um exame de si permanente e intenso, e, logo, pesaroso. E isso, eu acrescentaria, independentemente de se tratar de adulto ou criança.

Finalmente e, sobretudo, a própria criança não é passiva nisto tudo; ela seleciona, interpreta as experiências, constrói estratégias que podem conduzir a mudanças nas suas relações com seus pais e a revisões nas práticas destes. Há um efeito da experiência da criança sobre as práticas.

\section{O ponto de vista das crianças}

Nestes últimos tempos, o estudo da educação nas famílias trouxe sem dúvida matizes e reviravoltas no plano teórico. No plano prático, isso apenas pode interessar os pais e as pessoas que lidam com as famílias num plano profissional, contanto, obviamente, que a complexidade do fenômeno assim como os limites e as nuances que as pesquisas apontam sejam tomados em conta.

Nesta segunda parte gostaria de introduzir uma perspectiva que me parece essencial: o ponto de vista das crianças. Não seria interessante conhecer seu ponto de vista, no que diz respeito às práticas de socialização que lhes são destinadas? Independentemente de seu interesse, os trabalhos evocados aqui não nos dizem muita coisa a respeito de uma questão essencial: como a própria criança vive tudo isso, quais 
são seus próprios sentimentos, idéias e ações quando dos diversos processos educativos de que é objeto?

Inúmeras pesquisas em psicologia e pedagogia têm estudado a própria criança, mas interessaram-se essencialmente pelas suas características, pelo papel que seu sexo, idade, índole etc. pode desempenhar nas práticas educativas dos pais, assim como nas suas conseqüências. A criança foi geralmente considerada um objeto ou um idiota cultural. Levaram-se em conta suas características, mas não seu ponto de vista, sua experiência, nem a cultura particular que constrói com seus pares. Ora, alguns trabalhos recentes sobre a vida cotidiana das crianças e as microculturas infantis (Corsaro, 1997; Mayall, 1994), assim como a emergência de uma sociologia da infância (James et al., 1998; Sirota, 1998; Montandon, 1998; Montandon, 2001), mostram que as crianças sabem exprimir-se a respeito de suas experiências e que seus relatos matizam e completam o que sabemos sobre os processos educativos. Como toda e qualquer coletividade social, as crianças constroem e compartilham uma cultura que lhes é específica. Se, ao crescerem, abandonam inevitavelmente a coletividade de que fazem parte, outras vêm tomar seu lugar: o espaço das crianças sempre permanece e contém sua cultura. O que estas pensam nem sempre corresponde com o que os pais pensam que elas pensam. Entretanto, pensam, e seu pensamento não é inferior.

Pois a análise de crianças (...) não nos faz descobrir um ser mais simples mas uma outra complexidade; mais do que a atuação das pulsões em estado bruto ou os afetos numa forma rudimentar, ela nos mostra uma lógica tão sofisticada como a nossa mas com operações e, em parte, objetos diferentes.

A psicanálise não pode senão levar a cabo a mesma revisão, dilacerante ou não, que, há alguns tempos, a etnologia empreendeu: o pensamento selvagem não é um pensamento primitivo (...). (Pontalis, 1979, p. 12)

Ao levar muito mais em consideração o ponto de vista das crianças, o sentido que atribuem à sua socialização e a sua experiência, poderíamos avaliar melhor a influência da educação parental. Vimos que elas têm uma visão informada do papel e das qualidades dos que são encarregados de sua educação assim como do funcionamento das instituições educativas; elas exercem uma introspecção notável sobre seu próprio modo de aprender e de interagir com os outros. Isso é claramente 
ressaltado por dois estudos conduzidos em Genebra: um sobre a experiência que as crianças têm de sua própria educação e outro sobre sua experiência da autonomia (Montandon \& Osiek, 1997; Montandon \& Longchamp, 2003).

\section{O ponto de vista sobre as práticas educativas}

O primeiro estudo, com crianças entre 11 e 12 anos, ${ }^{2}$ mostrou que estas são capazes de análises muito finas. Concederam-nos entrevistas aprofundadas em sua casa e na escola, e recolhemos seu ponto de vista sobre as práticas educativas de seus pais e professores. Apresentaremos a seguir algumas análises a respeito de suas famílias e mais particularmente de suas expectativas com relação a seus pais.

Quase todas têm uma idéia clara do que esperam de seus pais: antes de tudo, amor, apoio, escuta, compreensão, consolo, sem esquecer humor. Logo, as expectativas de ordem afetiva e emocional estão entre as de primeira importância.

Também esperam uma "boa educação", isto é, que seus pais lhes indiquem como se comportar, como se controlar, tudo o que faz com que os outros possam dizer: "esta criança é bem-educada", e que lhes ensinam regras de interação com os outros, assim como padrões de autodomínio, ou seja, como se controlar. Algumas esperam de seus pais um estímulo à autonomia, um preparo para quando se tornarem "mais velhas". Outras gostariam que seus pais lhes dessem uma orientação (guidance) transmitindo-lhes valores como o amor, a escuta dos outros, a honestidade etc. $\mathrm{O}$ apoio escolar e o apoio material também são mencionados (Montandon \& Osiek, 1997).

Essas expectativas são realizadas? Um terço das crianças sente-se incondicionalmente apoiado por pais que se interessam por elas, as amparam, consolam, aconselham e até intervêm quando necessário. Contudo, para dois terços das crianças, o interesse e o apoio afetivo parental não são tão maciços. Algumas dizem receber apoio apenas quando pedem ou quando seus pais o julgam importante. Outras dizem que seus pais se interessam sobretudo pela execução correta das tarefas escolares e pelas suas idas e vindas, que não devem criar problemas. Para um pequeno número, o interesse dos pais erra o alvo pois é visto como uma intrusão. A oferta educativa dos pais, portanto, parece não corresponder 
plenamente com a demanda de sua prole. Embora as crianças ponham as dimensões morais e relacionais de suas expectativas em primeiro lugar; elas revelam, por exemplo, que seus pais, preocupados com a urgência, parecem conceder mais importância à gestão do cotidiano e ao êxito escolar. Sem dúvida, as crianças esperam afeto e apoio de seus pais, além de orientação (guidance) e segurança, mas, em seu cotidiano, sentem-se muito mais cercadas que amparadas, espreitadas que escutadas (idem, ibid.).

Elas não rejeitam todo controle por parte dos pais e, no plano dos comportamentos, até o esperam. Contudo, no plano psicológico, gostariam que seus pais fossem menos intrusivos (ver também Barber, 2002). Além do mais, as crianças são muito conscientes dos desejos de seus pais. Todavia, se algumas os internalizam, isso não ocorre às cegas. Quanto às escolhas para seu futuro, por exemplo, levam em conta as realidades sociais, entre as quais seus resultados escolares ou, ainda, analisam os prós e os contras de uma profissão pesarosa ou exigente demais.

No âmbito desse estudo, a importância dos colegas na socialização também surgiu de modo claríssimo nas entrevistas com as crianças. Neste ponto, nossa análise de seus discursos corrobora as análises de Harris (1995, 1998), mas também de outros trabalhos sobre o papel dos pares (Youniss, 1980), que salientam o peso das interações entre crianças, da microcultura do "povo" criança. Harris (1995), que examinou de modo sistemático os trabalhos psicológicos e psicossociológicos sobre os efeitos da educação parental, tentou reavaliar a influência parental situando-a no contexto ambiental global das crianças. Ao criticar os estudos baseados em correlações fracas e inconsistentes, ela chegou à conclusão de que, no conjunto das determinantes ambientais do desenvolvimento da personalidade e dos comportamentos da criança, os pares, ou seja, os colegas, contam mais que os pais (Harris, 1998). Como o papel que as outras crianças desempenhariam na socialização seria mais importante que o dos pais, ela preconiza que as pesquisas discriminem melhor a influência parental das outras explicaçôes possíveis antes de concluir que os pais modulam de maneira significativa a personalidade e os comportamentos de seus filhos. Os resultados de nosso estudo genebrino vão no mesmo sentido que a análise de Harris. Conseqüentemente, seria importante trabalhar não apenas sobre as relações que se estabelecem dentro da família, como também sobre as relações complexas com os pares, assim como com outros agentes externos de socialização. 


\section{A experiência da autonomia}

O segundo estudo enfocou a experiência que as crianças têm da autonomia. Inspirou-se no primeiro, o qual mostrou que, embora as crianças esperassem afeto e apoio por parte de seus pais, elas costumavam lutar para escapar de seu controle, e no fato de que a autonomia das crianças está no cerne dos debates sobre a crise associada à sua educação. Haveria crise, segundo alguns, porque se concedeu autonomia demais às crianças. Quem quer já tenha brigado pelos direitos da criança conhece esse debate. A indagação era a seguinte: numa cidade moderna como Genebra, será que o discurso pedagógico, herdeiro de Rousseau e Piaget, que apregoa o desenvolvimento da autonomia e condena o autoritarismo, é aplicado mesmo? E se for, quais seus efeitos? Deletérios, como afirma quem reclama mais autoridade? Vimos anteriormente que a maioria dos pais é favorável à aquisição da autonomia de seus filhos e que os pais estritamente autoritários constituem uma pequena minoria. Mas qual a experiência das crianças?

Pareceu-nos interessante buscar um melhor conhecimento da experiência diferencial que estas têm da autonomia assim como das condições sociais a ela subjacentes, em particular, da maneira como as pessoas que cuidam de crianças se situam com relação a essa autonomia. Como é possível, por exemplo, que em instituições como as escolas modernas, que afirmam levá-los à autonomia, os alunos estejam incessantemente expostos a decisões ou veredictos que não passam de juízos negativos contra sua capacidade de serem autônomos? Mais precisamente, essa pesquisa tinha dois objetivos principais:

a) examinar a experiência da autonomia que as crianças têm no âmbito de sua família e no da escola, ao repertoriar as diferentes formas de que se reveste assim como as situaçôes em que se concretiza. Apreender o que a autonomia significa para elas e analisar seu modo de tratar as exigências de autonomia de que são objeto. Analisar as diferentes experiências de autonomia das crianças segundo os contextos e segundo suas características sociais e culturais.

b) Estudar as representações da autonomia que pais e docentes têm e analisar as atitudes e exigências que manifestam para com as crianças a respeito da autonomia. ${ }^{3}$ 
Os dados foram colhidos com crianças de 11 a 12 anos por meio de questionários completados por entrevistas aprofundadas com 40 deles e por entrevistas de grupo. Seus pais e os docentes de suas escolas também participaram, mas, aqui, abordaremos principalmente alguns resultados relativos à experiência das crianças na sua família (Montandon \& Longchamp, 2003).

As crianças do estudo dizem que as regras existem, claro, mas que podem ser discutidas para certos aspectos da vida cotidiana. Os pais, portanto, não exigem sua submissão incondicional como costumava ser o caso no passado, o que corrobora as respostas dos pais, que mostram não abandonarem a autoridade, mesmo se esta é redefinida.

A autonomia subjetiva e factual das crianças apresenta algumas variações segundo o sexo, a composição da família ou o pertencimento social de seus pais. Assim, por exemplo, os filhos de pais operários têm uma representação subjetiva da autonomia menos forte que a dos filhos de pais de classe média ou executivos superiores e patróes. Em termos de ação, mais particularmente das atividades que implicam uma autonomia concreta (ir sozinho à cidade, cuidar de uma criança pequena, fazer suas lições sem pressão dos pais, trabalhar por dinheiro, dormir na casa de colegas), as diferenças segundo o meio ou o sexo variam em função das atividades e do tipo de responsabilidades implicadas. Por exemplo, cuidar de crianças menores é uma tarefa mais freqüente entre crianças cujos pais são operários ou têm uma formação pouco elevada, ao passo que ir dormir na casa de um(a) colega é uma atividade mais freqüente entre as crianças de classe média.

Segundo as crianças, os pais têm um papel crucial a desempenhar a respeito de sua autonomia. Vejamos o que respondem quando perguntadas sobre o que mais as ajuda a se tornarem autônomas. Os pais vêm em primeiro lugar, mencionados por uma forte maioria. Eles "dão responsabilidades; dão explicações para o futuro; encorajam a se virar; mostram e depois deixam fazer; dão confiança e ajudam a se organizar; dão bons conselhos; ensinam coisas que ajudam; deixam as crianças se virarem, dão o exemplo".

A escola, por sua vez, é mencionada por uma minoria, quatro crianças em dez. Ela "ensina a se organizar; dá tarefas nas quais é preciso se virar; dá responsabilidades; traz os conhecimentos que permitem ser ou se tornar mais autônomo”. 
Quase tanto quanto a escola, as dificuldades da vida são evocadas por um pouco menos de quatro crianças em dez. Segundo elas, "enfrentar as dificuldades leva à autonomia; as dificuldades obrigam a tomar decisóes; sem dificuldades, a gente deixa rolar; os erros cometidos permitem aprender para a próxima vez; sem dificuldades, não precisa ser independente".

Os irmãos e as irmãs são mencionados por duas crianças em dez; trata-se dos maiores, que são um pouco como pais. Os colegas também ajudam a se tornar autônomo nas mesmas proporções; conversa-se com eles e, às vezes, servem de exemplo. Em seguida algumas crianças falam das leituras, que permitem aprender coisas, dos esportes que levam a ultrapassar a si mesmo, do dinheiro que permite ser independente e, de maneira isolada, evocam o tempo que faz crescer, o contato com pessoas que sabem ser autônomas, o fato de se apaixonar ou de ganhar confiança em si e, finalmente, a televisão.

Parece, portanto, que os pais desempenham um papel muito importante na autonomia tal como concebida pelas crianças, ao criarem condiçôes e ao deixarem a criança ter suas experiências. O papel da escola é bem menor aos seus olhos, o que confirma um outro resultado da pesquisa: quando a autonomia ocupa um lugar central no projeto de uma escola, seus alunos não parecem aproveitar-se disso muito mais que os das escolas mais tradicionais.

Os pais também desempenham um papel importante na organização do tempo de seus filhos. Nosso estudo mostrou que, numa cidade como Genebra, onde o nível de vida é em média bastante elevado, boa parte do tempo livre das crianças é dedicada a cursos e esportes, à televisão, ao consumo em companhia de amigos. O fato de terem tantas oportunidades apresenta suas vantagens e seus inconvenientes. Vantagens, pois estas enriquecem sua bagagem, abrem portas para a autonomia tal como a entendem. Inconvenientes, pois são mais solicitadas do que antes por escolhas num contexto de vida mais diversificado. Portanto, esses estilos de vida, as visões do mundo, essa diversidade cultural enriquecem mas desnorteiam ao mesmo tempo, e tudo isso ocorre num contexto social muito competitivo.

As crianças mostram-se muito "filósofas": costumam pensar que, dada a sua situação de dependência no plano concreto, é melhor tentar fazer o que se espera delas e, embora tenham estratégias para ganhar inde- 
pendência na vida cotidiana, geralmente se conformam às exigências dos pais. Por sinal, e nisso se assemelham a estes, elas têm uma visão pragmática da autonomia; para a maioria entre elas, trata-se de adquirir independência no plano concreto, pois poucas a situam no plano da mente.

Em contrapartida, elas não se enganam quanto às contradições e aos numerosos hiatos entre os discursos e as intençôes dos adultos, mais particularmente a respeito das questôes de autonomia. Elas vêem claramente os ardis autoritários da pedagogia antiautoritária. Elas desejam mais autonomia, mas têm sentimentos ambivalentes; elas são sensíveis ao que as espera em sua vida de adulto e várias têm medo de crescer. De saída, sua experiência está imersa na ambivalência que caracteriza os indivíduos contemporâneos, ambivalência decorrente de uma busca paradoxal de autonomia e apoio, ao mesmo tempo, que marca sensivelmente sua própria atitude com relação à autonomia.

\section{À guisa de conclusão}

Os argumentos apresentados neste texto podem se resumir em alguns pontos:

1. As práticas educativas dos pais são muito diferentes e não existe um modelo único: os pais sempre fazem prova de autoridade (salvo algumas exceçôes - tutela, casos dramáticos etc.). Obviamente, os que empregam uma autoridade de tipo tradicional, estatutária, são hoje em dia relativamente pouco numerosos e, mais freqüentemente, trata-se de uma autoridade de orientação, ou de uma autoridade que se negocia. Contudo, mesmo nestes dois últimos casos, algumas coisas são autoritariamente proibidas às crianças.

2. Essas práticas dependem de muitos fatores, o quadro é complexo, e é preciso levar em conta o conjunto dessas variáveis e de suas interações caso se queira compreender sua evolução. Essa complexidade é hoje em dia amplamente reconhecida (Bril, 1999; Sabatier, 1999).

3. Os efeitos das práticas educativas dos pais sobre as crianças não são evidentes e não se pode dizer de maneira absoluta que tal ou tal estilo educativo é melhor ou produz bons resulta- 
dos. Tudo depende dos contextos e das situações. Ainda estamos longe de saber quais práticas são efetivas para que crianças e em que contextos.

4. O ponto de vista das crianças traz elementos indispensáveis à compreensão de sua experiência e é importante levá-lo em consideração. Sabe-se ainda muito pouca coisa, mas novos trabalhos nessa perspectiva poderão sem dúvida trazer, no futuro, um suplemento de sentido às pesquisas sobre a educação familiar. Além disso, também se deve considerar a experiência das crianças sob uma perspectiva geracional da infância. De fato, cada geração de crianças vive uma experiência coletiva particular. As da grande depressão dos anos de 1930 conheceram uma experiência diferente daquelas das grandes guerras, daquelas dos anos de 1950 etc. A experiência coletiva das crianças contemporâneas também tem sua especificidade: uma forte ambivalência. Além do mais, as crianças de hoje vivem em sociedades as quais permitem, mais que antes, que se discuta livremente, e que derrubaram a autocracia. Se elas parecem menos submetidas e mais críticas é porque estão sintonizadas com a evolução de sua sociedade. Entretanto, ao mesmo tempo, fazem parte do grupo das crianças: vivem, portanto, a relaçăo de poder assimétrica consubstancial à infância - são mais fracas perante os adultos, sem esquecer que, do ponto de vista econômico, são as primeiras a serem afetadas.

5. Apreender o ponto de vista das crianças levanta questôes metodológicas. Durante muito tempo, os sociólogos "desconfiaram" das crianças e as ciências sociais não têm uma longa tradição nesse campo. Assim, apesar de todas as precauçôes metodológicas e apesar do fato de os dados recolhidos com crianças não serem menos autênticos que os recolhidos com adultos, o investigador deve se perguntar se os aborda corretamente, e se os compreende e interpreta bem. Os psicólogos, que têm mais experiência com crianças, poderiam sem dúvida constituir interlocutores interessantes.

6. Finalmente, num plano político, essas observaçôes levam a pensar que aqueles que sustentam um discurso a respeito de uma crise da educação, devida à demissão dos pais ou à adoção de 
práticas educativas permissivas, representam um perigo muito maior do que o que denunciam. As pesquisas continuam mostrando que a educação autoritária não é a mais positiva - pelo menos, hoje em dia, quando a sociedade exige flexibilidade e espírito crítico de seus membros. Como ensinar os valores cidadãos de nossa época às crianças, se as criarmos numa família ou numa escola que ensinam a desigualdade e a submissão? Nas sociedades antigas ensinava-se obediência às crianças, na família e na escola, para que também estivessem prontas a obedecer no meio do trabalho e perante as autoridades. Se quisermos indivíduos adaptados à sociedade contemporânea que se tornou mais democrática, não seria lógico mudar também os modos de educação? Não seria lógico que as mudanças sociais representassem um certo custo e até certos sofrimentos particulares, que pedem tratamentos particulares?

Sem dúvida ainda falta muito para responder a estas diferentes indagaçôes que abordamos rapidamente aqui.

\section{Recebido em novembro de 2004 e aprovado em março de 2005.}

\section{Notas}

1. Essa comunicação enfoca principalmente as sociedades designadas como ocidentais e pós-industriais. Vale, portanto, ressaltar seus limites. Obviamente, existem crianças e pais em todos os lugares, mas a infância e a família são percebidas e vivenciadas diferentemente segundo as sociedades e as classes sociais.

2. A coleta de dados envolveu 68 crianças - 35 moças e 33 rapazes - de 4 turmas de quinta série da escola pública genebrina. As 4 classes foram escolhidas em 4 bairros diferentes, com crianças de todos os meios.

3. Os dados foram colhidos com crianças de 11 a 12 anos $(\mathrm{N}=388)$, e com seus pais $(\mathrm{N}=352$; taxa de resposta excepcional) e com os professores de suas escolas (Montandon \& Longchamp, 2003).

\section{Referências bibliográficas}

AMATO, P.R.; BOOTH, A. A generation at risk: growing up in an era of family upheaval. Cambridge: Mass: Harvard University, 1997.

BARBER, B.K. (Ed.). Intrusive parenting: how psychological control affects 
As práticas educativas parentais e a experiência das crianças

children and adolescents. Washington: American Psychological Association, 2002.

BAUMRIND, D. Effects of authoritative parental control on child behavior. Child Development, Chicago, v. 37, p. 887-907, 1966.

BAUMRIND, D. Current patterns of parental authority. Developmental Psychology Monographs, v. 4, n. 1, p. 2, 1971.

BAUMRIND, D. New directions in socialization research. American Psychologist, Washington, v. 35, p. 639-652, 1980.

BEST, D.K.; WILLIAMS, J. Sex, gender, and culture. In: Berry, J.; Segall, M.H.; KagitçiBasi, C. (Ed.). Handbook of cross-cultural psychology: social behavior and applications. 2 ed. Boston: Allyn and Bacon, 1997. v.3, p. 163-212.

BRIL, B. Dires sur l'enfant selon les cultures: etat des lieux et perspectives. In: BRIL, B. et al (Ed.). Propos sur l'enfant et l'adolescent: quels enfants pour quelles cultures. Paris: L'Harmattan, 1999. p. 5-40.

CHAO, R.K. Beyond parental control and authoritarian parenting style: understanding Chinese parenting through the cultural notion of training. Child Development, Chicago, v. 65, p. 1111-19, 1994.

CLARK, M. Family life and school achievement: why poor black children succeed or fail? Chicago: Chicago University, 1983.

CORSARO, W.A. The sociology of childhood. London: Pine Forge, 1997.

DORNBUSCH, S. et al. The relation of parenting style to adolescent school performance. Child Development, Chicago,v. 58, p. 1.244-1.257, 1987.

DU BOIS-REYMOND, M.; SUNKER, H.; KRUGER, H. Childhood in Europe: approaches-trends-findings. New York: Peter Lang, 2001.

ELIAS, N. The civilizing process: the history of manners and state formation and civilization. Oxford: Blackwell, 1993. (version allemande: 1937).

FONTAINE, A.-M. Pratiques éducatives familiales et motivation pour la réussite d'adolescents en fonction du contexte social. In: DANSEREAU, 
S.; Terrisse, B.; Bouchard, J.-M. (Ed.). Education familiale et intervention précoce. Montréal: Agence d'Arc, 1990. p. 209-224.

FURSTENBERG, F.F. Children and family change: discourse between social scientists and the media. Contemporary Sociology, Washington, v. 28, n. 1, p. 10-17, 1999.

GECAS, V. The influence of social class on socialization. In: BURR, W.R.; Hill, R.; Nye, F.I.; Reiss, I.L. (Ed.). Contemporary theories about the family. New York: Free, 1979. v.1.

GECAS, V.; BURKE, P. Self and identity. In: Cook, K.S.; Fine, G.A.; House, J.S. (Ed.). Sociological perspectives on social psychology. Boston: Allyn and Bacon, 1995.

HARRIS, J.R. Where is the child's environment?: a group socialization theory of development. Psychological Review, Washington, v. 102, n. 3, p. 458-489, 1995.

HARRIS, J.R. The nurture assumption: why children turn out the way they do. New York: Free, 1998.

JAMES, A.; JENKS, C.; PROUT, A. Theorizing childhood. Cambridge: Polity, 1998.

JONES, H.E.; BAYLEY, N. The Berkeley Growth Study. Child Development, Chicago, v. 12, p. 167-173, 1941.

KELLERHALS, J.; MONTANDON, C. Les stratégies éducatives des familles. Paris: Delachaux et Niestlé, 1991.

LAHIRE, B. Tableaux de familles. Paris: Gallimard, 1995.

MACCOBY, E.E. Social development: psychological growth and the parent-child relationship. New York: Harcourt Brace Jovanovich, 1980 .

MACCOBY, E.E.; MARTIN, J. Socialization in the context of the family: parent-child interaction. In: Hetherington, E.M.; Mussen, P.H. (Ed.). Handbook of child psychology. New York: Wiley, 1983. p. 1-101.

MAYALL, B. (Ed.). Children's childhoods: observed and experienced. London: Falmer, 1994. 
As práticas educativas parentais e a experiência das crianças

MONTANDON, C. La sociologie de l'enfance: l'essor des travaux en langue anglaise. Education et Sociétés, n. 2, p. 91-118, 1998.

MONTANDON, C. Sociologia da infância: balanço dos trabalhos em língua inglesa. Cadernos de Pesquisa, São Paulo, n. 112, p. 33-60, 2001 .

MONTANDON, C.; OSIEK, F. L'éducation du point de vue des enfants. Paris: L'Harmattan, 1997.

MONTANDON, C.; DOMINICÉ, L.; LIEBERHERR, R. Le point de vue des enfants sur la construction des liens sociaux: l'exemple de la violence entre élèves. Revue Suisse de Sociologie, Zurich, n. 2, p. 319-344, 2000 .

MONTANDON, C.; LONGCHAMP, P. L'expérience de l'autonomie chez l'enfant: une question récurrente dans la socialisation de l'enfant. Genève: Université de Genève, 2003.

PETERSON, G.W.; ROLLINS, B.C. Parent-child socialization. In: Sussman, M.B.; Steinmetz, S.K. (Ed.). Handbook of marriage and the family. New York: Plenum, 1987. p. 471-507.

PLOMIN, R.; CHIPUER, H.M.; NEIDERHISER, J.M. Behavioral genetic evidence for the importance of nonshared environment. In: Hetherington, E.M.; Reiss, D.; Plomin, R. (Ed.). Separate social worlds of siblings: the impact of nonshared environment on development. Hillsdale: Erlbaum, 1994. p. 1-21.

PONTALIS, J.-B. La chambre des enfants. In: Pontalis, J.-B. (Ed.). L'enfant. Paris: Gallimard, 1979. p. 7-17.

POURTOIS, J.-P.; DESMET, H. L'éducation familiale. Revue Française de Pédagogie, Paris, n. 88, p. 69-101, 1989.

RAMIREZ, M.I.; COX, B.G. Parenting for multiculturalism: a Mexican-American mode. In: Fantini, M.D.; Gardenas, R. (Ed.). Parenting in a multicultural society. New York: Longman, 1980.

RENAUT, A. La liberation des enfants: contribution philosophique à une histoire de l'enfance. Paris: Bayard-Calmann-Lévy, 2002.

ROUSSEL, L. L'enfance oubliée. Paris: Odile Jacob, 2001. 
SABATIER, C. Adolescents issus de l'immigration: les clichés à l'épreuve des faits. In: BrIL, B. et al. (Ed.). Propos sur l'enfant et l'adolescent: quels enfants pour quelles cultures. Paris: L'Harmattan, 1999. p. 357-382.

SINGLY, F. Le soi, le couple et la famille. Paris: Nathan, 2002.

SIROTA, R. (Ed.). Sociologie de l'enfance. Education et Sociétés, n. 2, p. 9-33, 1998.

YOUNISS, J. Parents and peers in social development. Chicago: Chicago University, 1980. 